Portland State University

PDXScholar

$10-1-2017$

\title{
A Simulation for Managing Complexity in Sales and Operations Planning Decisions
}

\author{
Scott DuHadway \\ Portland State University, duhadway@pdx.edu \\ David Dreyfus \\ Rutgers University
}

Follow this and additional works at: https://pdxscholar.library.pdx.edu/busadmin_fac

Part of the Business Administration, Management, and Operations Commons Let us know how access to this document benefits you.

\author{
Citation Details \\ DuHadway, Scott and Dreyfus, David, "A Simulation for Managing Complexity in Sales and Operations \\ Planning Decisions" (2017). Business Faculty Publications and Presentations. 93. \\ https://pdxscholar.library.pdx.edu/busadmin_fac/93
}

This Post-Print is brought to you for free and open access. It has been accepted for inclusion in Business Faculty Publications and Presentations by an authorized administrator of PDXScholar. Please contact us if we can make this document more accessible: pdxscholar@pdx.edu. 


\title{
A Simulation for Managing Complexity in Sales and Operations Planning Decisions
}

\begin{abstract}
Within the classroom it is difficult to convey the complexities and intricacies that go into making sales and operations planning decisions. This article describes an in-class simulation that allows students to gain hands-on experience with the complexities in making forecasting, inventory, and supplier selection decisions as part of the sales and operations planning process. The activity may be run during one class period and is flexible enough to accommodate almost any class size. During the simulation, students may apply forecasting techniques, inventory management concepts, and supplier selection processes, while experiencing the effects of supply chain disruptions. This simulation is recommended to be used after forecasting, inventory management, and supplier selection topics have been discussed. An overview of the exercise and evidence of its effectiveness is provided.
\end{abstract}

\section{INTRODUCTION}

Sales and Operations Planning (S\&OP) is an integrated business planning process in which managers gather and share information from different functional areas of the business, which can help lead to higher firm performance (Thomé, Sousa, \& Scavarda do Carmo, 2014). S\&OP provides an opportunity for an organization to match supply and demand, and it has been identified as an overlooked area of operations management texts (Maloni \& Franza, 2009) and a major content area to which supply chain students are underexposed (Grandzol \& Grandzol, 2011). Real-life business environments which explore complexity have been identified as valuable for reinforcing learned supply chain management (SCM) principles (Arora \& Saxena Arora, 2015). This article reports the implementation of an S\&OP simulation into supply chain courses to provide students with an opportunity to better understand and manage the complexities inherent in making the S\&OP process. The Excel files associated with this simulation may be found on the following website, http://wp.me/P8lPRP-y, or by contacting one of the authors. 


\section{Learning Objectives of the Simulation}

There are three learning objectives of the S\&OP simulation for students: (i) Understand the trade-offs inherent in the S\&OP process; (ii) Apply forecasting, inventory management, and supplier selection techniques to develop an S\&OP to manage these trade-offs; and (iii) Test the robustness of the S\&OP in conditions of uncertainty. Overall, the exercise emphasizes greater connectivity among the different parts of the S\&OP process through a simulation.

Trade-offs in SCM have been identified as an important decision criteria for managing a supply chain, especially in the presence of uncertainty (Prater, Biehl, \& Smith, 2001). Previous research has highlighted the difficulties of imparting the complexities of SCM decisions through traditional teaching methods, since most students do not have much work experience and are not trained to see the entire supply chain of a firm (Feger \& Thomas, 2011; Webb, Thomas, \& Liao-Troth, 2014). This challenge is exacerbated by the traditional teaching methods that often present topics independently in a course, limiting the students' opportunities to understand and experience the interdependencies inherent in SCM.

In the simulation, students are assigned to teams to manage decisions regarding the S\&OP process over twelve periods. The simulation emphasizes applying tools within a team-based setting to make effective decisions. Simulation-based learning environments enable students to generate relationships among the key components of the simulation as they engage in the role of decision makers to apply course concepts (Kang \& Doerr, 2015; Zantow, Knowlton, \& Sharp, 2005). Experiential learning enables illustrating "theoretical business and operations management concepts in practice by simulating the workings of an actual manufacturing organization” (Piercy, 2010).

The use of a simulation to connect complex content in business courses has been used to teach project management (Hartman, Watts, \& Treleven, 2013), inventory decision making (Umble \& Umble, 2013), and forecasting (Clark \& Kent, 2013; Snider \& Eliasson, 2013; Webb et al., 2014). Several other supply chain simulations exist, including Littlefield Technologies, which is a "factory simulator" 
(Responsive Learning Technologies, 2017a); The Supply Chain Game, which combines forecasting, production, and logistics (Responsive Learning Technologies, 2017b); the beer game (Sterman, 1989), which has been used extensively to teach about the bullwhip effect (Jacobs, 2000); and Harvard Business School’s Global Supply Chain Management simulation, which emphasizes forecasting and supplier selection based on cost and capacity (Harvard Business Publishing, 2016). While these simulations can be valuable learning tools, the lack of an available tool for addressing the S\&OP process integrated with supplier selection was the primary motivation for developing the simulation. The simulation presented in this manuscript emphasizes the trade-offs inherent in the S\&OP process and in supplier selection.

\section{THE SIMULATION ACTIVITY}

\section{Exercise Overview}

The simulation provides an opportunity for students to experience a simulated S\&OP process.

Throughout the simulation, the students will make the following decisions:

1. Forecasting: Students are provided 24 periods of demand data for four different products. Using methods of their choice, students then compute a demand forecast for each of the parts. In each period, students update the forecast as additional data is made available.

2. Inventory Management: Based on the generated forecasts, students must decide ordering times and quantities for each of the parts and manage inventory levels throughout the simulation.

3. Supplier Selection: Students must decide between suppliers to cover all of the four parts in each time period based on the supplier profiles provided in the simulation. They have the choice among four pieces of equipment and ten different suppliers, each with different profiles in terms of products offered, unit cost, startup costs, quality, disruption risk management, innovation, and timeliness.

The simulation is set up to run for 12 consecutive periods and engage in forecasting, inventory management, and supplier selection each period. Each decision is related and the teams must consider the 
full combination of information and choices together. Accurate forecasting is necessary for good inventory management, especially given the 2-period lead time. Both forecasts and inventory levels can help to determine optimal supplier strategies due to costs associated with various suppliers, including upfront setup costs, variable, and fixed period costs.

The simulation is played in teams of three or four students. Each team uses the Student Excel File to enter their decisions for each period on the Decision Sheet. Based on the decisions that students make each period, the inventory levels, costs, and revenues are calculated automatically by the Student Excel File. The students may evaluate their performance by tracking their net profit both cumulatively and in each period. The overall performance metric for each team is the cumulative net profit (or loss) at the end of the twelve periods.

The primary objectives of the simulation are provided to the students on a single sheet within the Student Excel File. Figure 1 shows a screenshot of the Decision Sheet, which is the primary interface that students have with the simulation. It includes the following components: period instructions (i), a table to enter forecasts (ii), a table to enter actual demand provided by the instructor (iii), a table to enter and look up event codes (iv), a place to enter orders for every product in each time period (v), a table to select active suppliers for every part in each period (vi), supplier information (shown in Table 1), and performance scores (not shown).

Insert Figure 1 Here

Insert Table 1 Here 
The instructor has a dedicated Instructor Excel File that should be projected on the classroom screen. In each period, the instructor reveals the actual demand and any external events that impact the supply chains of the teams. In addition, the instructor can record team performance for each period on a sheet in the Instructor Excel File or on a classroom board. The demand information provided in the simulation consists of several components (trends, seasonal adjustments, seasonal events, and a randomwalk stochastic component), and can be customized by the instructor for specific demand profiles as needed. In each time period, one random external event will be selected by the simulator from a pool of 32 possible events. Half of the events are positive and impact suppliers/equipment characterized by high scores for quality, high disruption risk management, high innovativeness, or high timeliness. The other half of the events are negative and impact suppliers/equipment which are characterized by low scores for each of the same characteristics. For every characteristic, there are four positive and four negative events, which include minor, medium, major, and critical events. A sample of events is provided in Table 2.

Insert Table 2 Here

As can be seen from the description of the simulation, the students make decisions in conditions of uncertainty. The uncertainty arises from the trade-offs inherent in the S\&OP process and supplier selection, unknown demand, and stochastic external events that occur every period. These trade-offs include:

- The typical trade-offs of Economic Order Quantity (EOQ) that exist between ordering costs, inventory carrying costs, and order quantities.

- The tradeoffs between higher inventory carrying costs and unfulfilled demand (stock-outs).

- The trade-off between the cost structures of equipment/suppliers and their performance in terms of quality/disruption risk management/timeliness/innovativeness profiles. 
- The trade-offs between the fixed costs associated with acquiring and maintaining a piece of equipment or establishing a new supplier relationship, variable unit costs, and flexibility in terms of the parts that the supplier can produce.

Students should be taught how to manage these trade-offs and should be given enough time to evaluate the information available to make better decisions. Student teams that understand the tradeoffs above and use appropriate decision-making strategies will outperform student teams who do not rely on those techniques. A short not exhaustive list of techniques (in alphabetical order) students could apply for the different decisions are included below:

- $\quad$ Forecasting: linear regression, linear regressions with period adjustments, moving averages using simple, weighted, or exponential smoothing approaches, and seasonal adjustments.

- Inventory management: aggregate planning, continuous or periodic review systems, EOQ, least total/unit costs, lot-for-lot ordering, and safety stock calculations.

- Supplier selection: analytical hierarchical process decision making, breakeven analysis, total cost analysis, and weighted average comparisons.

In each period of the simulation, students will update their decisions for inventory management and supply selection to respond to the actual demand levels within the simulation and the various events which occur to suppliers that have been selected. Students are exposed to consequences from the choices that they make in terms of costs during the simulation and events that are connected to the attributes of selected suppliers.

\section{Instructor Preparation}

The goal of this activity is to provide an opportunity for the students to utilize the tools they have learned in previous class sessions to make multiple decisions in the simulation, thus helping them see the sequence of inter-related decision that occur within a supply chain management process. During the 
simulation, the instructor manages the external factors that impact the teams during the simulation, including revealing actual demand information and the external event that occurs in each period.

The simulation instructions include an explanation of the simulation, recommendations of questions to ask the students, and an explanation of the Student Excel file that the students use in order to make decisions throughout the simulation. Given the complexity of the simulation, it is important that the instructor takes an active role in seeking out student questions, such as asking each team individually if they have any planning and decision questions during the early part of the simulation. This is useful, as it provides an opportunity for the instructor to gauge progress for timing each period, and students are more likely to ask questions to the instructor within their team rather than in front of the entire class.

Lastly, the instructor collects data regarding each team's performance, both for individual periods and at the end of the simulation. This provides benchmarking results and creates a dynamic of competition among the teams. It also provides an opportunity to provide token rewards to teams for performance throughout the simulation and a larger prize at the end for the best performing team. While the reward process can add an enjoyable competitive dynamic to the simulation, care must be taken to identify how short-term performance does not always match with optimal decision making, and sometimes the best decision for the long-run might lead to short-term losses, such as investing in a new piece of equipment. The reward process also serves as an opportunity to reflect on the experience, as discussed in a later section.

\section{Class Preparation}

It is recommended that students are aware of the critical concepts prior to engaging in the simulation. These include understanding various forecasting techniques, supplier selection decisions and tradeoffs, and inventory management for both S\&OP and Master Production Schedules (MPS). It is recommended that the simulation be used within the classroom after these topics are covered. To further assist with student preparation, students can be provided with materials prior to the simulation to allow them to 
practice the aforementioned concepts. This may aid them in preparation for any examination within the classroom, as well as provide them with experience using the tools necessary for making the types of decisions required during the simulation. To aid in this effort, the forecasting and supplier selection components of the simulation can be shared with students prior to the simulation activity to familiarize them with the data in the simulation.

Before the simulation begins, the students should be provided with the demand information from the simulation. The demand information included in the simulation has general trends, seasonal variation, and random variance. While students can use a variety of forecasting approaches, the most effective teams tend to use more advanced forecasting approaches, such as linear regressions, or exponential smoothing adjusted for seasonality.

Ideally, the supplier information is also shared with students ahead of time to allow students more time to evaluate the different strengths and weaknesses of the suppliers. Higher quality suppliers have tradeoffs of either higher costs per part, higher fixed or variable costs, or are able to supply fewer products. Students are asked to make tradeoff decisions regarding supplier selections, but multiple strategies may be effective. Each team is encouraged to select a company strategy to help guide them in choosing the suppliers that best fit with their vision and mission. For example, a low-cost strategy would be more likely to choose lower cost suppliers that were less innovative, but more timely.

Inventory management concepts, such as EOQ and the total inventory cost, can be calculated with the data provided in the Student Excel File. However, time limitations of the simulation tend to limit these calculations to the initial planning time period.

The simulation is designed in such a way that it can be used as a stand-alone single event using a single class period or broken into three individual segments (forecasting, supplier selection, and the simulation experience). Forecasting and Supplier Selection modules can be assigned via homework individually or in groups prior to the simulation experience, which might help prepare students for the 
experience. This will make the simulation experience flow more smoothly and take less time, as the students will already be familiar with some of the modules. However, this simulation can also be done with no prior preparation beyond teaching the required concepts if sufficient time is allocated for planning. Sample schedules for this simulation are provided in Table 3.

Insert Table 3 Here

\section{Exercise Debrief}

At the end of the simulation, it is important to help connect the students' experiences with their performance. This is done by asking each team to report on their performance, including challenges and successes throughout the simulation. The different strategies that students select provide them with useful learning experiences as they reflect on optimum forecasting approaches, risk-taking decisions, managing forecast errors and order variance, and the tradeoffs between fixed costs and variable costs for different supplier options. Typical responses include strategies focusing on one or two competitive dimensions from among cost, quality, timeliness, innovation, or disruption risk management. Students who choose to be the low-cost leaders and keep costs down will experience more negative events because their suppliers will have lower quality, timeliness, innovativeness, and/or disruption risk management scores. They may perform well for some of the periods, but they are at risk of having a poor event significantly affect them. Students who choose to focus on quality may incur higher upfront costs for the suppliers/equipment they choose. Students are asked to create a strategy and then experience the complexities and outcomes tied to the decisions they make.

These post-simulation discussions can yield valuable learning opportunities to discuss short-term versus long-term performance as a team, which allows discussion on how decisions that are financially beneficial in the short term are not necessarily better in the long run. Recording team performance in each 
period enables both quantitative and qualitative discussions of team performance. Probing questions to explore challenges and successes also provide an opportunity to explain how to effectively apply different tools for managing the different components of the simulated business across multiple products. Finally, a written summary of what worked well, what didn't work well, and what the team would do differently may be assigned.

\section{ASSESSMENT OF EFFICACY}

A version of this S\&OP simulation has been used in three undergraduate courses at two different universities by two different professors. Anonymous survey data was collected during the last two semesters in which the simulation was used (Spring and Fall 2016). On average, about $60 \%$ of the respondents are seniors and 73\% are supply chain management majors. Respondent ages ranged from 20 to 51. Specific respondent information is provided in Table 4 below.

Insert Table 4 Here

The simulation activity was largely similar between both samples, though improvements were made to the simulation following the first iteration at University 1 to help better accomplish the learning objectives and increase the value of the simulation. Students responded positively to the simulation. Selected statements were collected from students who experienced the simulation at University 1 and are provided below:

- "It put us in a real world situation where we work with teams to use our skills learned in the classroom.”

- "The activity did benefit my classroom experience by putting the textbook knowledge we have covered into actual practical application.”

- " "Engaged the classroom and gave us a visual experience of forecasting and ordering." 
- "By having a real-time simulation, it was easier to see how demand can affect inventory levels rather than just reading about case studies.”

- $\quad$ "It really put into perspective how much goes into every decision. There is a lot more than meets the eye when it comes to selecting suppliers.”

The positive learning experiences of the students was further measured at University 2 using modified questions based off the Hartman et al. (2013) perceptions of learning survey. The results are shown in Table 5. The results reveal that the activity was viewed as fun (5.97 out of 7.00 score on a balanced Likert scale) and as an engaging classroom exercise (6.03 out of 7.00). Additionally, the students agreed that the exercise improved their understanding of the importance of S\&OP (5.90 out of 7.00) and its key concepts (5.76 out of 7.00).

Insert Table 5 Here

\section{ACADEMIC AND MANAGERIAL IMPLICATIONS}

For persons teaching operations and supply chain management courses, this simulation provides an opportunity to integrate many concepts into one class exercise. Students find it fun and stimulating. It is important to expose students to real-life scenarios. This is often hard to do with the limited number of interactive class periods during a typical semester. This simulation provides the opportunity to expose students to situations that may occur at their current and future employers. It may provide them confidence to address future tasks assigned to them at their jobs and to better understand the potential pitfalls of various decisions. Finally, it helps expand their thinking beyond the linear processes that the curriculum often contains by having them consider decisions from multiple angles.

There is a need in industry for individuals to understand all the working parts of an organization and to realize how their decisions affect others. This simulation allows for students to better understand 
the steps and outcomes of their decisions on a supply chain. As one industry contact stated after learning of this simulation, "I wish my team could participate.” Another individual that works for a major construction equipment manufacturer stated,

“We still use Excel for much of our analyses. However, many of our analyses rely on qualitative reasoning, rather than textbook methods. It would be helpful to know how to test and implement various forecasting techniques and create better inventory management policies.”

These statements help lead to the conclusion that the concepts and tools being taught are useful and set students up for success. While many of the concepts in the classes may have been taught for decades, businesses are still in need of these ideas and tools. This simulation helps students practice their techniques and develop strategies to integrate several areas of a business.

\section{CONCLUSION}

Educators are facing pressure to provide opportunities to students to take learning beyond the classroom. By using simulations, one can achieve this in a low-cost, engaging manner. This simulation helps prepare students for positions within the field of SCM by providing them with a greater appreciation of the complexities and tradeoffs that are involved in the decision-making processes within S\&OP. Specifically, it requires a sequence of decisions to be made for a supply chain, so that value is maximized across the supply chain and not optimized locally.

Often in class exercises, assigned homework, and exams, the process to find the correct answer is linear and involves following the correct process for solving the problem. By participating in this exercise, students learn that determining an optimal strategy is not a simple process, and one must make tradeoffs to complete the task to the best of their abilities within the time frame provided. These insights are highly valuable for students to experience. It is valuable for them to understand and experience the tradeoffs involved in managing complexity and making decisions using limited information, resources, and time. This S\&OP simulation provides a meaningful experience that enhances student learning, in 
addition to providing a fun, engaging classroom opportunity to students, while reinforcing the concepts from the classroom instruction, so students are better prepared for their future careers. 


\section{REFERENCES}

Arora, A., \& Saxena Arora, A. (2015). “Supply Chain-Marketing Shark Tank” experiential lab game in interdisciplinary business education: Qualitative and quantitative analyses. Decision Sciences Journal of Innovative Education, 13(1), 21-43.

Clark, T. S., \& Kent, B. M. (2013). Forecasting: Exercises to enhance learning from business simulations. Decision Sciences Journal of Innovative Education, 11(2), 159-164. doi:10.1111/dsji.12000

Feger, A. L. R., \& Thomas, G. A. (2011). Bailing out the once-ler: Using Dr. Seuss to teach operations management. Decision Sciences Journal of Innovative Education, 9(1), 69-73. doi:10.1111/j.1540-4609.2010.00291.x

Grandzol, J. R., \& Grandzol, C. J. (2011). An experiential approach to benchmarking curriculum. Decision Sciences Journal of Innovative Education, 9(3), 401-409.

Hartman, N. S., Watts, C. A., \& Treleven, M. D. (2013). Appreciating the complexity of project management execution: Using simulation in the classroom. Decision Sciences Journal of Innovative Education, 11(4), 323-334. doi:10.1111/dsji.12016

Harvard Business Publishing (Producer). (2016, May 9, 2017). Global supply chain management V2 simulation. Retrieved from http://ctl.mit.edu/sites/ctl.mit.edu/files/attachments/tab\%204\%20SC_Simulation_How_to Play.pdf

Jacobs, F. R. (2000). Playing the beer distribution game over the internet. Production and Operations management, 9(1), 31.

Kang, K., \& Doerr, K. H. (2015). A classroom exercise to examine the trade-off between mission capacity and life cycle cost. Decision Sciences Journal of Innovative Education, 13(1), 3-20.

Maloni, M. J., \& Franza, R. M. (2009). Applying sales and operations planning to the MetroAtlanta water crisis. Decision Sciences Journal of Innovative Education, 7(2), 505-510.

Piercy, N. (2010). Experiential learning: The case of the production game. Decision Sciences Journal of Innovative Education, 8(1), 275-280.

Prater, E., Biehl, M., \& Smith, M. A. (2001). International supply chain agility-tradeoffs between flexibility and uncertainty. International Journal of Operations \& Production Management, 21(5/6), 823-839.

Responsive Learning Technologies. (2017a, May 9, 2017). Littlefield Technologies and Littlefield Laboratories. Retrieved from http://www.responsive.net/littlefield.html

Responsive Learning Technologies. (2017b, May 9, 2017). The supply chain game. Retrieved from http://responsive.net/supply.html 
Snider, B. R., \& Eliasson, J. B. (2013). Beat the instructor: An introductory forecasting game. Decision Sciences Journal of Innovative Education, 11(2), 147-157.

Sterman, J. D. (1989). Modeling managerial behavior: Misperceptions of feedback in a dynamic decision making experiment. Management Science, 35(3), 321-339.

Thomé, A., Sousa, R., \& Scavarda do Carmo, L. (2014). The impact of sales and operations planning practices on manufacturing operational performance. International Journal of Production Research, 52(7), 2108-2121.

Umble, E., \& Umble, M. (2013). Utilizing a simulation exercise to illustrate critical inventory management concepts. Decision Sciences Journal of Innovative Education, 11(1), 13-21. doi:10.1111/j.1540-4609.2012.00364.x

Webb, G. S., Thomas, S. P., \& Liao-Troth, S. (2014). Teaching supply chain management complexities: A SCOR model based classroom simulation. Decision Sciences Journal of Innovative Education, 12(3), 181-198. doi:10.1111/dsji.12038

Zantow, K., Knowlton, D. S., \& Sharp, D. C. (2005). More than fun and games: Reconsidering the virtues of strategic management simulations. Academy of Management Learning \& Education, 4(4), 451-458. 


\section{APPENDIX A: SUPPLIER SELECTION SIMULATION STUDENT INSTRUCTIONS}

Your team has been assigned the task of making sure demand for the next year is met for your company's key product lines. In years past, production has been outsourced overseas, but the company recently decided to start producing the products themselves. You have been tasked with selecting the suppliers and managing the ordering process over the next year to make sure you can meet customer demand and be as profitable as possible. To do that, you will need to select the right equipment or suppliers to meet demand. You have four different products to manage: Product A, Product B, Product C, and Product D.

The company has provided you with some information to help you make the decisions in an Excel file. In the Excel file, you will find the following sheets:

1. "Decision Sheet” - Primary sheet for all decisions and data input. Includes quick reference of useful data at the bottom.

Forecast - Area to include updated forecasts for each part as the simulation progresses.

\begin{tabular}{|c|c|c|c|c|c|c|c|c|}
\hline Forecast & Period -1 & Period 0 & Period 1 & Period 2 & Period 3 & Period 4 & Period 5 & Period 6 \\
\hline Product A & & & 1000 & 1225 & 1250 & 970 & & \\
\hline Product B & & & 500 & 650 & 550 & 667 & & \\
\hline Product C & & & 300 & 325 & 500 & 435 & & \\
\hline Product D & & & 200 & 200 & 225 & 145 & & \\
\hline
\end{tabular}

Actual Demand - Area to include actual order information as provided by the instructor in each period.

\begin{tabular}{|c|c|c|c|c|c|c|}
\hline Actual Demand & Period 1 & Period 2 & Period 3 & Period 4 & Period 5 & Period 6 \\
\hline Product A & 1225 & 1250 & 870 & & & \\
\hline Product B & 650 & 550 & 667 & & & \\
\hline Product C & 325 & 500 & 435 & & & \\
\hline Product D & 200 & 225 & 145 & & & \\
\hline
\end{tabular}

Event Information - Area to report event codes for each period and to look up a specific event. 


\begin{tabular}{|c|c|c|c|c|c|c|c|}
\hline Event Information & Period 1 & Period 2 & Period 3 & Period 4 & Period 5 & Period 6 & Period 7 \\
\hline Code & 7 & 12 & 3 & & & & \\
\hline \multirow{2}{*}{\multicolumn{8}{|c|}{ Event Lookup }} \\
\hline & & & & & & & \\
\hline Code & \multicolumn{7}{|l|}{3} \\
\hline Event Type & \multicolumn{7}{|l|}{ Quality } \\
\hline Event Severity & \multicolumn{7}{|l|}{ Major } \\
\hline Event Description & \multicolumn{7}{|c|}{ You received a high quality reward for your organization. } \\
\hline Condition & \multicolumn{7}{|c|}{ Every product supplied by a supplier with quality $\geq$ Very High } \\
\hline Event Effects & \multicolumn{7}{|c|}{ Receive $\$ 10,000$ as a period adjustment for each applicable product } \\
\hline Instructions & \multicolumn{7}{|c|}{ Add 10,000 to the current period in column E on the Performance Sheet for each product impacted } \\
\hline
\end{tabular}

Order Inventory - Area to indicate orders placed in that time period to arrive two periods later.

\begin{tabular}{|l|cccccc|c|}
\hline Order Inventory & Period -1 & Period 0 & Period 1 & Period 2 & Period 3 & Period 4 & Period 5 \\
\hline Product A & 1000 & 1000 & 1000 & 1225 & 1250 & 870 \\
Product B & 500 & 500 & 500 & 650 & 550 & 667 \\
Product C & 300 & 300 & 300 & 325 & 500 & 435 \\
Product D & 200 & 200 & 200 & 200 & 225 & 145 \\
\hline
\end{tabular}

Active Suppliers - Area to indicate suppliers selected for each part in every time period.

\begin{tabular}{|l|llll|}
\hline Active Suppliers* & \multicolumn{1}{|c|}{ Period 1 } & Period 2 & Period 3 & Period 4 \\
\hline Product A & Supplier 5 & Supplier 5 & Supplier 5 & Supplier 5 \\
Product B & Supplier 4 & Supplier 4 & Equipment 2 & Equipment 2 \\
Product C & Equipment 2 & Equipment 2 & Equipment 2 & Equipment 2 \\
Product D & Supplier 5 & Supplier 5 & Supplier 5 & Supplier 5 \\
*Leave active supplier selection blank if no order is placed in any given period for a specific part. \\
\hline
\end{tabular}

2. "Historical Demand" - Shows the demand for the last twenty four periods for all products and will update automatically based on new information. Revealed demand below does not match that in the simulation.

\begin{tabular}{|llrrrr|}
\hline Period & Date & Product A & Product B & Product C & Product D \\
Period -23 & January, 2015 & 384 & 232 & 80 & 0 \\
$\quad \ldots$ & & & & & \\
Period -2 & October, 2016 & 1250 & 550 & 500 & 225 \\
Period -1 & November, 2016 & 870 & 667 & 435 & 145 \\
Period 0 & December, 2016 & 1026 & 648 & 432 & 351 \\
Period 1 & January, 2017 & 1225 & 650 & 325 & 200 \\
Period 2 & February, 2017 & 1250 & 550 & 500 & 225 \\
Period 3 & March, 2017 & 870 & 667 & 435 & 145 \\
Period 4 & April, 2017 & & & & \\
Period 5 & May, 2017 & & & & \\
Period 6 & June, 2017 & & & & \\
\hline
\end{tabular}


3. “Performance Sheet” - Tracks costs per period and net profits by product. Also includes detailed information and cost calculations by product.

\begin{tabular}{|c|c|c|c|c|c|c|c|c|}
\hline & & & & & Product $A$ & Product B & Product C & Product $\mathrm{D}$ \\
\hline Period & Total & $\begin{array}{l}\text { Supplier } \\
\text { Fixed Costs }\end{array}$ & $\begin{array}{l}\text { Supplier } \\
\text { Period Costs }\end{array}$ & $\begin{array}{l}\text { Period } \\
\text { Adjustments }\end{array}$ & Net & Net & Net & Net \\
\hline 1 & $(35,050)$ & $(\$ 47,000)$ & $(\$ 4,050)$ & $\$ 0$ & $\$ 5,875$ & $\$ 2,750$ & $\$ 1,975$ & $\$ 5,400$ \\
\hline 2 & 12,925 & $\$ 0$ & $(\$ 4,050)$ & $\$ 0$ & $\$ 7,525$ & $\$ 3,100$ & $\$ 1,075$ & $\$ 5,275$ \\
\hline 3 & 13,512 & $\$ 0$ & $(\$ 1,050)$ & $\$ 0$ & $\$ 7,320$ & $\$ 2,465$ & $\$ 1,200$ & $\$ 3,577$ \\
\hline 4 & & $\$ 0$ & $(\$ 1,050)$ & $\$ 0$ & & & & \\
\hline 5 & & $\$ 0$ & $\$ 0$ & $\$ 0$ & & & & \\
\hline 6 & & $\$ 0$ & $\$ 0$ & $\$ 0$ & & & & \\
\hline 7 & & $\$ 0$ & $\$ 0$ & $\$ 0$ & & & & \\
\hline 8 & & $\$ 0$ & $\$ 0$ & $\$ 0$ & & & & \\
\hline 9 & & $\$ 0$ & $\$ 0$ & $\$ 0$ & & & & \\
\hline 10 & & $\$ 0$ & $\$ 0$ & $\$ 0$ & & & & \\
\hline 11 & & $\$ 0$ & $\$ 0$ & $\$ 0$ & & & & \\
\hline 12 & & $\$ 0$ & $\$ 0$ & $\$ 0$ & & & & \\
\hline & & & & & & & & \\
\hline Total & $(8,614)$ & & & & & & & \\
\hline
\end{tabular}

4. Inventory Sheets (one for each Product A - D) - Simple S\&OP chart for managing current and incoming inventory levels. Has some columns which will be modified as needed by events which occur in the simulation.

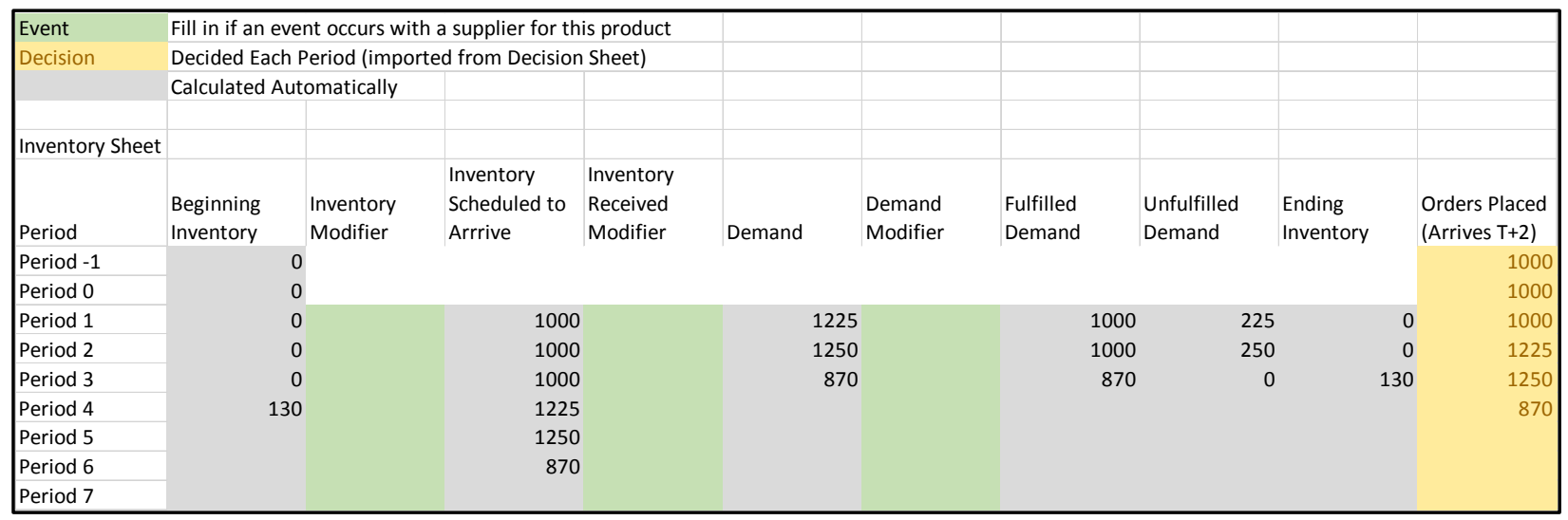

5. “Supplier Management Sheet” - Provides information for selecting suppliers and shows supplier costs for every period. 


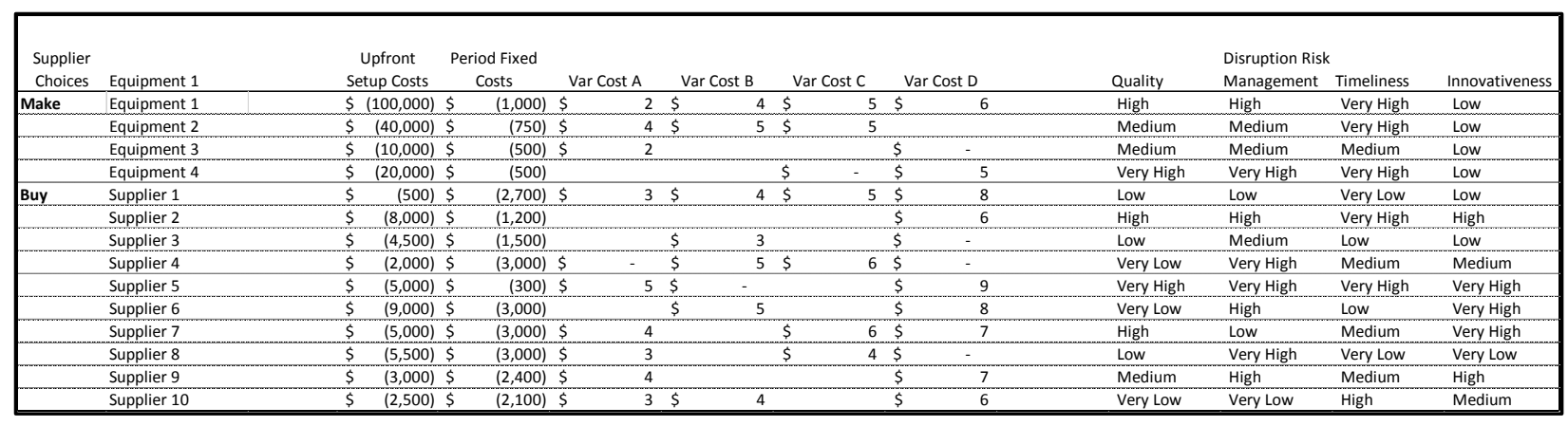

6. "Product Pricing Sheet” - Shows breakdown for product costs and revenues.

\begin{tabular}{|l|r|r|r|r|}
\hline Product A & \multicolumn{3}{|c|}{} & \\
\hline Period & Material Costs Event Modifier Variable Labor Costs & Sell Price & ICC (Per Period) \\
\hline Period 1 & 5 & $\$ 5$ & $\$ 15$ & $20 \%$ \\
\hline Period 2 & 5 & $\$ 5$ & $\$ 15$ & $20 \%$ \\
Period 3 & 5 & $\$ 5$ & $\$ 15$ & $20 \%$ \\
\hline Period 4 & 5 & $\$ 5$ & $\$ 15$ & $20 \%$ \\
\hline Period 5 & & $\$ 5$ & $\$ 15$ & $20 \%$ \\
\hline Period 6 & & $\$ 5$ & $\$ 15$ & $20 \%$ \\
\hline
\end{tabular}

Your job is three-fold:

1. Analyze historic demand and use a forecasting approach for ordering quantities for products A-D.

2. Select the equipment or supplier to manufacture or supply products A-D in each time period.

3. Manage inventory levels for products A-D.

\section{In every period, you will have to make the following decisions:}

1. Select the supplier to use for each product.

2. Place orders for each product.

3. Update demand information and forecasts.

4. Enter event number and follow event instructions, if applicable.

Your performance will be evaluated based on the total net income of the team's inventory management plan over the course of the year. Here are some hints: 
- During the simulation, good and bad events will occur which will impact different suppliers based on their qualifications. Selecting suppliers or equipment that are good or bad in an area will expose you to these positive or negative events.

- Products A, B, C, and D are all different. Consider looking at their demand patterns separately. They also have different carrying costs, profit margins, and costs to manufacture. This might change your strategies for ordering each product. More information is provided on the Product Pricing Sheet for the breakdown between products.

- Watch what is happening and be ready to adjust plans as necessary. But remember, you have 2 periods of lead time that slow down your reaction for any decisions that you do make. 


\section{APPENDIX B: SUPPLIER SELECTION SIMULATION INSTRUCTOR INSTRUCTIONS}

\section{The Learning Objectives}

1. Understand the trade-offs inherent in the S\&OP process.

2. Apply forecasting, inventory management, and supplier selection techniques to develop an S\&OP to manage these trade-offs

3. Test the robustness of the S\&OP in conditions of uncertainty.

\section{$\underline{\text { Simulation Outline }}$}

4. Provide simulation materials (assign pre-simulation modules, distribute the Student Excel file and student instructions).

5. Assign teams of 3 or 4 individuals.

6. Introduce the simulation by discussing student responsibilities of forecasting, inventory management, and supplier selection.

7. Run through a small hypothetical example where you do the following steps:

a. Generate a simple forecast:

i. Insert a line graph for a single part number.

ii. Generate a simple forecast (naïve forecast, lifetime average)

b. Place an order for that part on the Decision Sheet.

c. Select a supplier that can produce that part.

d. Announce an actual demand scenario.

e. Show updated inventory sheet on part table and final costs for the period for that part on the performance tab.

8. Have students play period 1: 
a. Tell students to develop a forecasting methodology and forecast for the first time periods, select suppliers, and place orders for the four parts for the periods that occur prior to period 1 to pre-order inventory for periods 1 and 2.

b. Visit each team to observe behavior and answer questions during period 1 .

c. After students have placed all orders, reveal actual demand and the event which occurs in period 1.

9. Play periods 2-12. In each period, students’ primary responsibilities include:

a. Select the supplier they are using for each part

b. Place orders for each part

c. Update demand information and forecasts

d. Follow event instructions if applicable

10. Report final scores.

11. Lead classroom discussion:

a. Teams that performed well, what worked for you?

b. Teams that did not end up as top performers, what happened? Why was it difficult?

c. What challenges did you run into?

d. If you adjusted your strategy, how difficult was it to adjust strategies in the middle of the simulation?

e. What additional information did you wish you had available? Did you have enough/too much information?

f. What tools did you use in making decisions at the start of the simulation? At the end?

The entire simulation can be done in an 80-minute class. It can be shortened in many ways to adjust to specific schedules (faster periods, fewer parts, or fewer time periods) as necessary. Sample simulation schedules are provided in Table 3. 
Table 1: Supplier selection choices

\begin{tabular}{|c|c|c|c|c|c|c|c|c|c|c|c|c|}
\hline \multicolumn{13}{|c|}{ Supplier Choices } \\
\hline & \multicolumn{3}{|c|}{ Upfront Setup } & Period Fixed & \multirow[b]{2}{*}{ Var Cost A } & \multirow[b]{2}{*}{ Var Cost B } & \multirow[b]{2}{*}{ Var Cost C } & \multirow[b]{2}{*}{ Var Cost D } & \multirow[b]{2}{*}{ Quality } & \multicolumn{2}{|l|}{ Disruption Risk } & \multirow[b]{2}{*}{ Innovativeness } \\
\hline & Supplier Options & & Costs & Costs & & & & & & Management & Timeliness & \\
\hline \multirow[t]{4}{*}{ Make } & Equipment 1 & $\$$ & $(100,000)$ & $(1,000)$ & $\$ 2$ & $\$ 4$ & $\$ 5$ & $\$ 6$ & $\mathrm{High}$ & High & Very High & Low \\
\hline & Equipment 2 & $\$$ & $(40,000)$ & (750) & $\$ 4$ & $\$ 5$ & $\$ 5$ & & Medium & Medium & Very High & Low \\
\hline & Equipment 3 & $\$$ & $(10,000)$ & $(500)$ & $\$ 2$ & & & & Medium & Medium & Medium & Low \\
\hline & Equipment 4 & $\$$ & $(20,000)$ & (500) & & & & $\$ 5$ & Very High & Very High & Very High & Low \\
\hline \multirow[t]{10}{*}{ Buy } & Supplier 1 & $\$$ & $(500)$ & $(2,700)$ & $\$ 3$ & $\$ 4$ & $\$ 5$ & $\$ 8$ & Low & Low & Very Low & Low \\
\hline & Supplier 2 & $\$$ & $(8,000)$ & $(1,200)$ & & & & $\$ 6$ & High & High & Very High & High \\
\hline & Supplier 3 & $\$$ & $(4,500)$ & $(1,500)$ & & $\$ 3$ & & & Low & Medium & Low & Low \\
\hline & Supplier 4 & $\$$ & $(2,000)$ & $(3,000)$ & & $\$ 5$ & $\$ 6$ & & Very Low & Very High & Medium & Medium \\
\hline & Supplier 5 & $\$$ & $(5,000)$ & (300) & $\$ 5$ & & & $\$ 9$ & Very High & Very High & Very High & Very High \\
\hline & Supplier 6 & $\$$ & $(9,000)$ & $(3,000)$ & & $\$ 5$ & & $\$ 8$ & Very Low & High & Low & Very High \\
\hline & Supplier 7 & $\$$ & $(5,000)$ & $(3,000)$ & $\$ 4$ & & $\$ 6$ & $\$ 7$ & High & Low & Medium & Very High \\
\hline & Supplier 8 & $\$$ & $(5,500)$ & $(3,000)$ & $\$ 3$ & & $\$ 4$ & & Low & Very High & Very Low & Very Low \\
\hline & Supplier 9 & $\$$ & $(3,000)$ & $(2,400)$ & $\$ 4$ & & & $\$ 7$ & Medium & High & Medium & High \\
\hline & Supplier 10 & $\$$ & $(2,500)$ & $(2,100)$ & $\$ 3$ & $\$ 4$ & & $\$ 6$ & Very Low & Very Low & High & Medium \\
\hline
\end{tabular}


Table 2: Selected Event List

Event

Classification Severity

+/- Event Description

Effect

Disruption Risk Management

Minor

There was some disruption due to storms, but your company was able Gain $10 \%$ increased demand from customer appreciation for 1 to manage it effectively. period

\begin{tabular}{|c|c|c|c|c|}
\hline Quality & Medium - & & $\begin{array}{l}\text { High quality product yielded more usable components than expected, } \\
\text { increase inventory received for the period by }+10 \% \text {. }\end{array}$ & $+10 \%$ inventory received for the period \\
\hline Timeliness & Major & + & $\begin{array}{l}\text { Effective inventory management has led to a reduction of } \$ 10,000 \text { of } \\
\text { expenses in your warehouse. }\end{array}$ & $\begin{array}{l}\text { Receive a one time } \$ 10,000 \text { period adjustment for each } \\
\text { applicable product }\end{array}$ \\
\hline Innovativeness & Critical & + & $\begin{array}{l}\text { Your supplier's innovation has changed the way they manufacture } \\
\text { their products making their products much cheaper. }\end{array}$ & $\begin{array}{l}\text { Variable costs decrease by } \$ 1 \text { for the rest of the game for each } \\
\text { applicable product }\end{array}$ \\
\hline $\begin{array}{l}\text { Disruption Risk } \\
\text { Management } \\
\end{array}$ & Minor & - & $\begin{array}{l}\text { The supplier had a disruption with their own supply network and can } \\
\text { no longer provide all product types. }\end{array}$ & $\begin{array}{l}\text { This supplier can no longer provide products A or B for three } \\
\text { periods }\end{array}$ \\
\hline Quality & Medium & - & A review of your inventories found bad inventory. & $\begin{array}{l}20 \% \text { of your held inventory must be discarded for the current } \\
\text { period }\end{array}$ \\
\hline Timeliness & Major & - & $\begin{array}{l}\text { The shipment is late, but you are able to expedite the shipment at a } \\
\text { cost of } \$ 10,000 \text {. }\end{array}$ & Incur $\$ 10,000$ additional costs \\
\hline Innovativeness & Critical & - & $\begin{array}{l}\text { A new innovative change to Products A an D was released in the } \\
\text { market, but your supplier cannot keep up with the change. }\end{array}$ & This supplier can no longer supply product A or product D \\
\hline
\end{tabular}


Table 3:

Sample Schedules for Facilitating Simulation for 80 Minute Classes

$\begin{array}{lc}\text { One Class } & \text { Minutes } \\ \text { Introduction } & 5 \\ \text { Initial Analysis } & 10 \\ \text { Round 1 } & 10 \\ \text { Discussion } & 5 \\ \text { Rounds 2-10 } & 45 \\ \text { Conclusion } & 5 \\ \text { Total } & 80\end{array}$

\section{Multiple Classes}

First class - Forecasting

Assign Forecasting Module 5

Second class - Supplier Selection

Assign Supplier Selection Module 5

Third class - Simulation Day

Introduction 5

Initial Analysis 5

Round 1

Discussion 5

Rounds 2-10 45

Conclusion

Total

10

80 
Table 4:

\begin{tabular}{|lcc|}
\hline \multicolumn{3}{|c|}{ Respondent Profiles } \\
\hline Age (Years) & University 1 $(n=32)$ & University 2 $(n=69)$ \\
Gender & 21.5 & 24.0 \\
$\quad$ Female & & \\
$\quad$ Male & $40.6 \%$ & $24.6 \%$ \\
Ethnicity & $59.4 \%$ & $75.4 \%$ \\
$\quad$ White & & \\
$\quad$ Hispanic or Latino & $71.9 \%$ & $30.4 \%$ \\
$\quad$ African American & $6.3 \%$ & $18.8 \%$ \\
$\quad$ Asian or Pacific Islander & $0.0 \%$ & $7.2 \%$ \\
$\quad$ Other & $21.9 \%$ & $39.1 \%$ \\
Grade Level & $0.0 \%$ & $4.3 \%$ \\
$\quad$ Junior & & \\
$\quad$ Senior & $43.8 \%$ & $37.7 \%$ \\
Major (\% SCM) & $56.3 \%$ & $62.3 \%$ \\
Work Experience (Years) & $75.0 \%$ & $71.0 \%$ \\
\end{tabular}


Table 5: Survey results from Fall 2016 classes $(n=70)$

\begin{tabular}{|l|r|r|}
\hline Questions & Mean & SD \\
\hline The SOP simulation was a worthwhile learning experience. & 5.93 & 1.52 \\
\hline $\begin{array}{l}\text { The SOP simulation was a more effective way to present the topic of SOP than the traditional } \\
\text { lecture format. }\end{array}$ & 5.71 & 1.65 \\
\hline $\begin{array}{l}\text { The SOP simulation was a great way to learn about how my decisions would impact team and } \\
\text { business process. }\end{array}$ & 5.89 & 1.57 \\
\hline The SOP simulation improved my understanding of key concepts in SOP. & 5.76 & 1.59 \\
\hline The SOP simulation improved my understanding of the importance of SOP. & 5.90 & 1.56 \\
\hline The SOP simulation helped me learn about SOP. & 5.88 & 1.61 \\
\hline The SOP simulation helped me apply course concepts. & 5.96 & 1.53 \\
\hline The SOP simulation was an engaging classroom exercise. & 6.03 & 1.42 \\
\hline The SOP simulation was fun. & 5.97 & 1.49 \\
\hline
\end{tabular}

*7-point Likert scale was used. Strongly Disagree $=1$; Strongly Agree $=7$ 
Figure 1: Decision Sheet

\begin{tabular}{|c|c|c|c|c|c|c|c|c|c|}
\hline Color Key & \multicolumn{2}{|r|}{ Period } & \multirow[b]{2}{*}{ Period 0} & \multirow[b]{2}{*}{ Period 1} & \multirow[b]{2}{*}{ Period 2} & \multirow[b]{2}{*}{ Period 3} & \multirow[b]{2}{*}{ Period 4} & \multirow[b]{2}{*}{ Period 5} & \multirow[b]{2}{*}{ Period 6} \\
\hline Generated by Forecasting Method & Forecast & Period -1 & & & & & & & \\
\hline Provided by Instructor & Product $\mathrm{A}$ & & & 1000 & 1225 & 1250 & 870 & & \\
\hline Decisions Required & Product B & & & 500 & 650 & 550 & 667 & & \\
\hline \multirow[t]{2}{*}{ General Information } & Product C & & & 300 & 325 & 500 & 435 & & \\
\hline & Product D & & & 200 & 200 & 225 & 145 & & \\
\hline First Period & Actual Demand & & & Period 1 & Period 2 & Period 3 & Period 4 & Period 5 & Period 6 \\
\hline Build Forecasting Models & Product A & & & 1225 & 1250 & 870 & & & \\
\hline Select Suppliers & Product B & & & 650 & 550 & 667 & & & \\
\hline \multirow[t]{2}{*}{ Place initial inventory orders for Products A-D } & Product C & & & 325 & 500 & 435 & & & \\
\hline & Product D & & & 200 & 225 & 145 & & & \\
\hline \multicolumn{10}{|l|}{ Subsequent Periods } \\
\hline Record Actual Data and Supplier Events & Event Information & & & Period 1 & Period 2 & Period 3 & Period 4 & Period 5 & Period 6 \\
\hline Update Forecasting Models with New Data & Code & & & 7 & 12 & 3 & & & \\
\hline \multicolumn{10}{|l|}{ Update Supplier Relationships } \\
\hline \multirow[t]{20}{*}{ Place inventory orders for Products A-D } & Event Lookup & & & & & & & & \\
\hline & Code & & & \multicolumn{6}{|l|}{3} \\
\hline & Event Type & & & \multicolumn{6}{|l|}{ Quality } \\
\hline & Event Severity & & & \multicolumn{6}{|l|}{ Major } \\
\hline & Event Description & & & \multicolumn{6}{|c|}{ You received a high quality reward for your organization. } \\
\hline & Event Effects & & & \multicolumn{6}{|c|}{ Receive $\$ 10,000$ as a period adjustment for each applicable product } \\
\hline & Condition & & & \multicolumn{6}{|c|}{ Every product supplied by a supplier with quality $\geq$ Very High } \\
\hline & Instructions & & & \multicolumn{6}{|c|}{ Add 10,000 to the current period in column E on the Performance Sheet for each product impa } \\
\hline & & & & & & & & & \\
\hline & Order Inventory & Period -1 & Period 0 & Period 1 & Period 2 & Period 3 & Period 4 & Period 5 & Period 6 \\
\hline & Product $\mathrm{A}$ & 1000 & 1000 & 1000 & 1225 & 1250 & 870 & \multirow{4}{*}{$\mathbf{V}$} & \\
\hline & Product B & 500 & 500 & 500 & 650 & 550 & 667 & & \\
\hline & Product C & 300 & 300 & 300 & 325 & 500 & 435 & & \\
\hline & Product D & 200 & 200 & 200 & 200 & 225 & 145 & & \\
\hline & Active Suppliers* & & & Period 1 & Period 2 & Period 3 & Period 4 & Period 5 & Period 6 \\
\hline & Product A & & & Supplier 5 & Supplier 5 & Supplier 5 & Supplier 5 & & \\
\hline & Product B & & & Supplier 4 & Supplier 4 & Equipment 2 & Equipment 2 & $v^{i}$ & \\
\hline & Product C & & & Equipment 2 & Equipment 2 & Equipment 2 & Equipment 2 & & \\
\hline & Product $\mathrm{D}$ & & & Supplier 5 & Supplier 5 & Supplier 5 & Supplier 5 & & \\
\hline & \multicolumn{7}{|c|}{ *Leave active supplier selection blank if no order is placed in any given period for a specific part. } & & \\
\hline
\end{tabular}

